\title{
Study on the Preventive Measures of College Network Group Events
}

\author{
Yafen $\mathrm{HaO}^{1}$
}

${ }^{1}$ Xi'an International University, Xi'an, Shaanxi, 710077

KEYWORDS: Universities; Network Group Events; Countermeasures

\begin{abstract}
The public opinion situation of college network group event is barometer of harmonious campus, harmonious society. Through the establishment of an effective mechanism for grooming, network public opinion to guide public opinion and improve the regulatory mechanism to further optimize the public opinion environment Universities.
\end{abstract}

\section{Introduction}

Grooming is based on education and the educated to establish a good relationship, around the psychological, ideological problems, mutual understanding, communication and guidance to eliminate barriers and promote the sound development of the way of things. In ancient China, "coffin division biography articles" described in the Road "touched the evil dead music students who did not. Inform its defeat, its good to say it, it will be guided by, open them with their pain, although have the road who do not listen to the evil there is peace! "analysis of Western psychoanalysis treatment proposed to tell catharsis, enlighten insight, suggesting that the main guide way as counseling, psychological counseling with somewhat similar. College Network group events occurred in large part because college students encounter or event of interest there is a certain deviation in the ideological issues, there is a certain psychological confusion. Based on this, we need to educate college students counseling. Applying this approach educators from the care, love respect departure educated, careful to understand the behavior and the situation faced by the educated mental confusion, neither blocked to speak up, but also good guide, educated and common psychological analysis root of the problem and the resulting formed and is actively encouraging the educated speak psychological doubts, to help them enhance their understanding, to find ways to solve their psychological doubts.

One of the root causes of the outbreak of the university network group events that college student ideology a mob behavior in the face of the existence of some kind of event. So how to solve this phenomenon. Students can actively grooming speech, according to the dispersion guide, step by step guide and, separately and mediated manner.

Dispersion guide for some of the group members thought the problem co-existing, decentralized manner, educate and guide one by one, by solving ideological, psychological problems of each member to resolve the issue of co-existence. In such a way can the student population in the presence of some kind of emotional, ideological problems, psychological problems piecemeal, reducing cross-infection between members of the group can focus on education and breakthroughs in focus, to achieve educational results achieved overall purpose. And step by step guide for groups personally important personnel, such as a personal opinion leaders ideological problems, mental confusion, according to priorities, there are steps to educate and guide. Ideology, mental confusion formation Students ideology formation, especially opinion leaders, for the occurrence of mass incidents university network plays a key role. Therefore, in front of many complex contradictions, 
and primary and secondary points have, step by step step by step and gradually solve the problem of key figures of key ideas, psychological problems, and gradually solve the problem most people's minds, mental confusion. Separately and guide, is to mobilize forces or a variety of educational personnel Group Events key figure, once a key figure in the outstanding problems that exist separately boot. These guiding a main key is to encourage the free airing of College Network Group Events opinion leaders or participants to gradually resolve the ideological and psychological problems.

Ancient Art of War says, "skilled persons, it's because of potential profit guidance." Universities in the network group events in ideological and political education of college students, to solve ideological problems, psychological problems, but also to correctly analyze the situation, according to their different characteristics and trends of thought, select the appropriate time to resolve them.

First, we must grasp the trend of the development of the university network group events, always grasp the state of mind of college students, guide and promote its ideology in the right direction, we cannot violate the laws of social development thinking. Secondly, we must grasp the occurrence of phase College Network Group Events, select the appropriate time, to master the furnace, choose the hair, do not miss the favorable opportunity of education, the development direction bias malignant College Network group events nipped in the bud. Third, we must make full use of favorable conditions for the hardware and software of modern media to overcome the negative factors, and give full play to the development of the vast majority of college students ideologically motivated positive factors, thereby bringing the event to the benign development.

Ancient "Learning" is mentioned in the "Road Frydman led by strong suppression Frydman, open and Fuda." His point is that clear reason, but do not be carried away by force; strict requirements, but do not apply pressure; show the way but do not replace the conclusions. Enlightenment and guidance, the emphasis is to play an active initiative of college students, college students inspire positive thinking and enhance college students to receive education initiative.

In the university network in group events, according to the survey, $63.1 \%$ of the students believe that the root causes of bandwagon effect. A fundamental reason for the occurrence of the bandwagon effect is that the enthusiasm of college students to think independently not excited, not enough education initiative. Based on this, we need this part of the college student targeted education. First of all, to ask questions, the university network group events cause specific grounds raised, Requirements for Students analyze, ponder. To enable them to use the correct theory of independent thinking, learn to analyze and solve problems, and thus will not blind conformity, to join the network of group event. Secondly, we must carry out discussions. For group events may cause things to discuss, requiring university students to express their views, inspire each other, exchange ideas and draw reasonable conclusions. Third, we must convince the front. With facts and methods so that students distinguish right from wrong, convinced that truth and resist error.

Of course, the establishment of an effective mechanism for grooming also need cause College Network Group Events fundamental analysis, specific guidance based on specific reasons.

\section{The Establishment of An Effective Network Public Opinion Guidance Mechanism}

Internet public opinion is the sum of the subject network audiences in the online space through a network of language and other means of public affairs around the hot social or general concern expressed emotions, attitudes and opinions. Public opinion to guide the network mainly for the important issues of the network group events have occurred or are likely to occur in the way of the proposed guidance, solutions and the like. 
Establish an effective mechanism to guide network public opinion, on the one hand the need for professional ideological and political education team; the other hand, also need to have an effective network of public opinion to guide the way.

Internet public opinion relates mainly to guide the team full-time ideological and political education management personnel, but also active in the real world and the virtual world of opinion leaders.

Management is a people-oriented ideological and political education, team-building and management of its relationship to the ideological and political education goals, objectives, process, evaluation, and leadership ability to get implemented, but also on the major issues of ideological and political education can achieve results. Mao Zedong once pointed out that the factors determining the political line, cadres are determined. Therefore, we need to build a politically strong, professional, disciplined, and work style of combining part-time public opinion to guide the team.

Excellent guide public opinion survey team needs to have a strong research capacity. To understand the methods of social surveys, attention to empirical research, good contacts, observe, understand, analyze educational objects and network environment, and make the right decision. To have a good ability to ideological propaganda. Do network public opinion guidance, the need to have a passion, patience, meticulous, able to seize the key to form a network group events. To have a strong organization and coordination ability. Can use a variety of educational forces, play together education. Able to carry out a variety of patient and painstaking work, we can use a variety of measures, through appropriate management, excited at the network group events parties conscientiously carry out ideological struggle, to achieve the transformation of ideological contradiction, thereby enabling the university network able to benign group events development of. To have the ability to use modern instruments. The rapid development of science and technology, expanding the scope of practice of human activities, coupled with the rapid development of information technology, requires ideological and political education, particularly specialized personnel network public opinion guidance, need to learn to use modern means of modern technology for humanity learn timely communication with people on the road to rapid development of information and quick completion of the ideological and political education management tasks.

Internet public opinion is mainly aimed at guiding the way things causing College Network Group Event has occurred or has not occurred, the way a certain targeted states of its occurrence and the impact of the formation. Including, control methods and the conversion mode.

Regulation by mainly refers to the university network caused mass incidents of network public opinion formation, development, and all aspects of the decline of the outbreak of a planned, purposeful way of implementation of the monitoring, analysis, adjustment and control taken.

Ex ante regulation by the net, which is the network of public opinion in order to prevent hot topics, go into a speech beforehand prevention mechanism network. Basically, the occurrence of mass incidents university network, often with specific events that exist in reality are closely linked. Under the net by the majority of participants in the discussion group events, expressed emotions, attitudes, opinions, rooted in the real world phenomena and problems. These phenomena and problems in the network in general is still relatively good control. Therefore, it is necessary to establish monitoring public opinion and Prevention System in Colleges under the net to strengthen the reality of public opinion collection and sorting analysis, and then be judged, to the maximum extent possible to resolve the phenomenon of public opinion may form a major cyber incidents and problems through social reality in a variety of effective ways to guide and resolve, so that there is a 
demand of the students demands, emotional, unhappy to be released to prevent inappropriate comments and information into the network.

Online business in a regulated manner for the network has been emerging network group events, we need something in the regulation of the online mode. On the one hand we must promptly remove possible formation of bad information network public opinion, in particular, to promptly remove sensitive, provocative, erroneous error message. The information spread to the Internet, is likely to be people with ulterior motives, thereby causing large-scale network group events. On the other hand, to timely track, grasp the relevant hot spots, focus reprint information, dissemination, diffusion, and to information, and thus the occurrence of the event to make the right judgments. Finally, we need to take the initiative to guide, control information, to strengthen the extreme behavior and speech correction, focus on the aggregation of speech analysis, and strengthen efforts to guide information, give full play to the role of opinion leaders, so that online information form a positive public opinion.

Under the net post a regulated manner for the network as reflected in the event, the need for timely regulation under the net post. With the continuous development of information technology, people's lives are often online and offline interaction ways. Internet public opinion in the negative information tends to attract more attention to college students. If the negative public opinion to the lack of effective control and guide, may cause the net event. Based on this, we need to network public opinion as reflected in the tendency of targeted regulation, timely monitoring network public opinion into real acts of the time, place, manner and the like, take effective measures to deal with the aftermath, to avoid creating new net mass incidents.

Conversion mode mainly refers to the ideological and political education for university network participant group events taken prompted their emotions, attitudes, thinking and behavior into a positive way of development.

Transformation and use emotional information disapprove of. Network audience, which is involved in Network group events, they formed feelings, opinions, ideas, etc. are based on certain cognitive basis. Therefore, it is necessary transformation of negative emotions and thought some of the audience. This requires an emotional departure, and close proximity network audience, strengthen emotional communication, enhance emotional identity, and then open its ideas into a channel guide that receives the correct, positive opinions and information.

Using double-sided reasoning and promote internalization combination. Sided reasoning is from the positive and negative aspects of reasoning, both the positive and negative opinions presented simultaneously. Communication Studies show that, compared with single-sided double-sided reasoning, with greater immunity. Therefore, through the dissemination of information, facts and truth, to correct the wrong information, and methods are laid out, make the network audience compared identification. Of course, we should believe that the vast majority of college students are sensible, the ability to analyze and judge, and is willing to accept the right information. Promote internalization is to guide the audience in the face of complex speech and behavior, rational judgment can be overcome extreme, choosing the right, adhere to positive, progressive network public opinion.

Behavior control and transformation of the way. Mainly rely on a code of conduct or behavior control to complete the conversion. Thought Transformation is a long and complex process, in addition to probation emotional reasoning, but also to regulate the behavior of the network audience.

\section{Improve the Network Public Opinion Monitoring Mechanism}


With the continuous development of network technology, the Internet, since the media has become a university student daily life utensils. In the genesis and development of the university network group events, the Internet, since the media has played a key role. In order to prevent network group events, we need to network, since the media are emerging network public opinion supervision and management. Strengthen the supervision of the network of public opinion, public opinion to prevent network flooding occurred university network group events, played a key role.

To build a network of public opinion monitoring mechanism, as well as to organize the network public opinion monitoring, but also for network public opinion study them, and the establishment of early warning system.

Establish a network public opinion monitoring mechanism, on the one hand to establish a department to collect public opinion. The main responsibility of this department is to collect, organize our students' network public opinion, organize them, and so judged. Personnel in this sector is mainly comprised of school party committee propaganda department, student management, ideological and political teachers and other related personnel. Required by the duty classification, a dedicated staff to collect information, analyze information personnel. These need to have the appropriate ability, one must have a strong network technology, but also for a better understanding of school policies, to see the problems highlighted in the network. Second, the organization and coordination capacity. According to individual strengths division of labor, the specific work assigned to specific personnel, to clarify their respective responsibilities. Strengthening mutual ties and cooperation among its members, subject to the scheduling of the entire department. On the other hand, we need the help of network tools for network public opinion were collected.

For a network to collect public opinion department collected information is usually public opinion is complex and chaotic mix of true and false, and therefore, you need to have a dedicated staff of public opinion to study them. Should organize them, evaluate the content and form. Finishing process is the process of organization of information, the purpose is to make information becomes orderly disorder, become the form of easy to analyze utilization. Evaluation is the process of sorting out the information in the original process value judgment of public opinion, the purpose is to filter out valuable information, and eliminate useless information. Evaluation and finishing the interaction proceeds, so that the collected information to become public opinion to facilitate the analysis of information. For the form of finishing is generally not involved in the content, simply by virtue of some external basis, such as different formats or information collection channels and other information. And organize the content is to further deepen the basis of finishing the form, in essence, it is public opinion digestion and absorption process.

After the above information for the network consolidation and evaluation of public opinion, to carry out a series of work has been prepared for the analysis of the network of public opinion. For the nature of information to be collated in-depth analysis of public opinion, reveal the problem, identify the root cause of these problems is formed, propose solutions to problems, and guide public opinion countermeasures. But also on the hands of network public opinion on the whole grasp, identify its universality, the tendency of things, be able to provide information for decision-makers of public opinion development.

Warning information is public opinion in the state of social prosperity, public opinion on the basis of the information collection and analysis, for society to run close to the negative value of the degree of deterioration of the critical uncertainties made early warning. In colleges and universities, the network of public opinion is warning information network public opinion on Universities for analysis, judgment, assessment, early warning information forming public opinion, for what might 
happen to make preparations. Establishment of early warning mechanisms can achieve the purpose of network public opinion on the incident prevention and control to some extent.

Based early warning system to establish a network of public opinion, according to organize public opinion before the collected information, analyzing, analyzes the development trend of public opinion, and thus find the source of the university network group events that may occur. Public opinion through the relevant network information collection system, information network public opinion analysis system, expert analysis system, and monitoring and evaluation system for network public opinion, public opinion further organized into early warning program, report to the school authorities.

School-related departments in dealing with the network group events, especially for major events, emergencies, need to cooperate with each other, communicate with each other, and then to develop a more detailed and effective criteria and early warning programs.

College Network group events as the Internet age a special group events, its prevention has become an important issue needs of the education sector. Based on this, on the university network group events rational analysis and propose effective preventive measures is especially important.

With the continuous development of Internet technology, especially the emergence of new media, university network group events become one of the university management topics concern. Universities as a train socialist builders and successors of the important places, university health network group events, public opinion is harmonious campus, harmonious society barometer. In order to ensure harmony and stability of colleges and universities, training of qualified personnel for socially useful, we must properly handle the occurrence of the most active groups in the social network group events.

\section{Acknowledgements}

Proj: 2015 Annual Shaanxi Provincial Department of Education Science Research Program "Universities Network Group Events Prevention Mechanism Research" Initial Results.

Project NO. 15JK2114

\section{References}

[1] [UK] Dennis McGuire, Liu Yannan translated. audience analysis [M]. Beijing: China Renmin University Press. 2009: 2-3.

[2] [Fr.] Gustave Le Bon, wearing light-years translated mob psychology study of mass [M]. Beijing: New World Press, 2010.

[3] [Fr.] with Serge Moscovici, Xu Liemin translated mob era [M]. Nanjing: Jiangsu People's Publishing House, 2006 edition

[4] [UK] Dennis McGuire, [Sweden] Sven Dahl Wen, Zhu Jianhua translated. Mass Communication Theory [M]. Shanghai: Shanghai Translation Publishing House, 1987 edition.

[5] Yu Jianrong, Contentious Politics - China Political Sociology fundamental problems [M]. Beijing: People's Publishing House in 2010. 